\title{
Intercultural linguistics as a new academic approach to communication
}

\author{
Marcel Pikhart ${ }^{1 \mathrm{a}}$ \\ ${ }^{1}$ Faculty of Information Technology and Management, Department of Applied Linguistics, University \\ of Hradec Kralove, Hradec Kralove, 500 03, Czech Republic
}

\begin{abstract}
Intercultural linguistics theoretically describes communicative principles which create the basis for intercultural communication. Languages serve as communicative tools and in the current globalized world they always exist in the context of other languages and cultures. Applied linguistics provides us with many theoretical and practical strategies for communication, however, the paper claims that it is the intercultural linguistics, as a new academic pursuit, which should and could provide us with more sophisticated tools for communication to succeed in the global village we live in.
\end{abstract}

Keywords: Intercultural linguistics;intercultural communication; business communication; linguistics; communication

\section{Intercultural linguistics, communication and social}

Intercultural linguistics theoretically describes communicative principles which create the basis for intercultural communication. Knowing the universal sociopragmatic interactional principles means that we know the importance of individual speech acts inasmuch they influence everyday communication by attaching various meanings to the words we say.

Particular languages, contexts and cultures thus create the space not only for information transfer but also the space for mutual understanding. In intercultural social interactions it is crucial to be aware of the perception of various concepts such as directness vs. indirectness and situational appropriateness in each society. Communication then creates the relationship between the interlocutors either conflicting or consensual. The cultural context creates the framework in which "the doing of politeness is embedded and the value system which enable speakers and hearers both to do and interpret politeness" [3].

${ }^{\text {a }}$ Corresponding author: marcel.pikhart@gmail.com

(C) The Authors, published by EDP Sciences. This is an open access article distributed under the terms of the Creative Commons Attribution License 4.0 (http://creativecommons.org/licenses/by/4.0/). 


\section{Business communication principles}

As Spencer-Oatey [5] claims, the essential sociopragmatic interactional principles comprise equity and association. The equity is understood as a fundamental belief through which we feel entitled to personal consideration from others. Such a consideration, we presume, should save us from inappropriate treatment by our counterparts, which may involve imposing on us or ordering us about, using us for someone's advantage, etc. There are two notions are closely tied with this area: the issue of cost-benefit and another one of autonomy-imposition. The former deals with aspects of exploitation and disadvantage and the latter with the degree of control we tolerate from others.

The association is defined as a belief due to which we expect social involvement with others. The association rights relate partly to interactional involvement-detachment behaviours, which is manifested through the degree of conversational interaction and chitchat with others. The unpleasant extremes may be resistance to integrate on one hand and overwhelm the amount of integration on the other. Another aspect of association relates to affective involvement-detachment area addressing issues of shared concerns, feelings and interests through which one may feel either isolated or integrated within a particular community.

Both the groups of sociopragmatic principles are culturally biased. The degree of understanding a particular speech act rests in exercising the appropriate amount and intensity of the equity and association, which brings us back to the eternal cultural question of appropriateness. The appropriateness necessary differs according to the sociocultural norms and individual preferences.

To see the problem issue from another perspective, we may use the viewpoint of the classic rhetoric and its three essential components: ethos, logos and pathos. All the three components define the degree of understanding and belief the interlocutors exercise over a conveyed message, particular utterances and speech acts.

- Ethos refers to the ethical appeal of the speaker, to their trustworthiness and credibility often based on previous experience and record.

- Logos addresses the logical appeal of the message, its internal consistency and integrity.

- Pathos is associated with the emotional appeal. It refers to the ability to evoke sympathy and images of the speech acts in audiences' and interlocutors 'minds. Seen through this perspective it seems evident, that both ethos and pathos are highly subjective categories firmly embedded in the cultural context of a particular speaker and their audience. The only category aspiring to possess a quality of an objective evaluation potential is the logos area which can, to a certain degree, resemble the transactional content of the rapport management defined by [5].

\section{Implementing intercultural business communication in the university curriculum: Czech Republic Universities case study}

Trying to implement the basic principles of intercultural linguistics and intercultural business communication the author of the paper managed to introduce the subject Intercultural Business Communication in the Global Environment (IBCGE) to the curriculum of the Faculty of Information Technology and Management, University of Hradec Kralove, Czech Republic, and University of Pardubice, Czech Republic, in the academic year 2012/13. Now the subject has been taught for two years for both Czech and foreign students each semester.

The IBCGE subject contains of one 45-minute lecture and a seminar intended for the students of information management, finance management and management of leisure and 
tourism. Naturally, it is taught in English as the majority of participating students are from abroad studying in the Czech Republic. It focuses on modern forms of business communication in the global business environment in the last decade and draws attention to opportunities and possible threats of doing business globally. It also highlights new trends in intercultural (transcultural or cross-cultural) management.

The basic points to deal with during the lectures are:

- Communication and culture

- Studying intercultural communication

- Cultural influences on context: The business setting

- Intercultural communication in an evolving business context

- Becoming competent: Improving intercultural communication

- The global manager's environment

- Managing interdependence

- The cultural context of global management

- Cross-cultural negotiations and decision making

- Implementing strategy for international and global operations

- Global alliances and strategy implementation

- Global human resources management

The subject is based on current authoritative literature in the field of intercultural management, transcultural management and cross-cultural management (but also new trends in ICT [1, 2, and 4]). All these terms are used interchangeably as the majority of the authors do not describe significant differences. The credit is given for an oral presentation covering national cultural stereotypes the students represent according to the country of their origin and/or their personal cultural clash/clashes they have experienced both personal and business. The exam is based on theoretical knowledge based on the reading assignments given to the students at the beginning of the course.

The feedback of the participants both during and after the semester was very positive. Almost all of them expressed their satisfaction with the content and the outcomes of the course in the anonymous questionnaire. The added value of the course was the fact that they now feel to be more aware of the cultural diversity and the fact that it can heavily influence not only personal relationship with other people but also their business performance and results. Being more culturally aware is a benefit for them making them more adaptable to the world global forces enabling them to communicate and act more efficiently in the global marketplace.

\section{Conclusion}

Intercultural linguistics as a new academic discipline can help us to create or make us aware of the communicative principles which create the basis for intercultural communication. Languages and their representation in communication serve as tools which enable us to convey meaning and therefore applied linguistics and intercultural linguistics can be the tool for enhancing communication in the current globalized world where the cultures and languages meet in an intense and unprecedented way.

Applied linguistics provides us with many theoretical and practical strategies for communication, however, the paper claims that it is the intercultural linguistics, as a new academic pursuit, which should and could provide us with more sophisticated tools for communication to succeed in the global village we live in. 


\section{References}

1. Černá, M. , Poulová, P., Social Software Applications and their Role in the Process of Education from the Perspective of University Students. e-Learning : proceedings of the 11th European conference. Reading : Academic publishing, 2012. 10s. ISBN: 978-1908272-74-4. ISSN: 2048-8637, (2012)

2. Černá, M.: G. , Poulová, P., Reflection of Comenius' didactic principles in ESP instruction. ICIBET 2013 : international conference on Information, business and education technology. Paris : Atlantis press, 2013. 4s. ISBN: 978-90-78677-56-7, (2013).

3. Hickey, L. and Stewart, M. (ed.), Politeness in Europe. Clevedon: Multilingual Matters, Ltd., (2005).

4. Maresova, P., Kacetl, J., Innovations in ICT in the Czech Republic with Focus on a Chosen Region. Procedia Social and Behavioral Sciences, Vol. 109, pp. 679-683, (2014).

5. Spencer-Oatey, H., Culturally Speaking. Culture, Communication and Politeness Theory. London: Continuum, (2008). 